\title{
Transbronchial biopsy without fluoroscopy: a five year experience in outpatients
}

\author{
OLIVIER DE FENOYL, FREDERIQUE CAPRON, BERNARD LEBEAU, \\ JACQUES ROCHEMAURE
}

From the Clinique de Pneumologie et Laboratoire Central d'Anatomo-Pathologie, Hotel-Dieu de Paris, Paris

ABSTRACT Transbronchial biopsy is the technique of choice for obtaining tissue for histologica: diagnosis in many pulmonary disorders. The procedure has usually been carried out as an inpatiens procedure with the use of fluoroscopy, though this policy has recently been questioned. This repore concerns a five year experience of 174 transbronchial biopsies performed without fluoroscopy as an outpatient procedure in patients with interstitial lung disease or a suspicion of sarcoidosis. Ches? radiography was carried out only if the patient developed symptoms. No major complications werథ encountered and the overall complication rate was low. Pneumothorax occurred in six patiente (3.4\%), only one of whom required intercostal intubation, and bleeding of more than $30 \mathrm{ml}$ occurreq in two patients. Histological diagnosis was obtained in 154 patients $(88 \%)$. In the experience of thiso group transbronchial biopsy has been safe when carried out as an outpatient procedure withoute fluoroscopic guidance.

\section{Introduction}

Fibreoptic bronchoscopy with transbronchial biopsy is commonly used at an early stage in the investigation of interstitial lung diseases. ${ }^{12}$ It is associated with a low incidence of complications and can be performed without general anaesthesia. ${ }^{13-5}$ The safety of transbronchial biopsies has been under discussion for some years and two points are still a matter of debate: the necessity of fluoroscopic guidance and the feasibility of carrying out the procedure in outpatients.

The American Thoracic Society recommended the use of fluoroscopy during transbronchial biopsy to prevent pneumothorax, though recently this recommendation has been deleted. ${ }^{6}$ Recent studies have concluded that transbronchial biopsy is safe when performed without fluoroscopy. ${ }^{7-9}$ The second point under discussion is whether transbronchial biopsy is safe when carried out as an outpatient procedure or whether patients should be admitted to hospital. The safety of fibreoptic bronchoscopy has been recognised in many studies; ${ }^{3-1011}$; but some still consider that transbronchial biopsy requires admission to hospital ${ }^{10}$ whereas others disagree, concluding that hospital

Address for reprint requests: $\operatorname{Dr} O$ de Fenoyl, Clinique de Pneumologie, Hotel-Dieu de Paris, 1 Place du Parvis Notre-Dame, 75004 Paris, France.

Accepted 25 July 1989 admission solely for transbronchial biopsy is un necessary. ${ }^{1213}$

This report represents our experience with trans? bronchial biopsy carried out without fluoroscopy aबे an outpatient procedure over a five year period.

\section{Methods}

From March 1983 to June 1988 we performed fibrea optic bronchoscopy with transbronchial biopsy in 178 outpatients. During the same period 188 patients who had been admitted to hospital underwent transbrong chial biopsy; nearly all had been admitted for persona or technical reasons (transfer from another hospitab residence far away, other investigations). Only $2 \bar{\phi}$ subjects were admitted to hospital for a medicat reason: unstable cardiopulmonary condition, severe pulmonary function impairment (arterial oxygeơ tension $<9.3 \mathrm{kPa}(70 \mathrm{~mm} \mathrm{Hg})$ ), abnormal coagiro lation, pregnancy. All procedures were performed bo the same operator in the same bronchoscopy suite. Aff patients were referred for investigation of an inter stitial lung disease or a suspicion of sarcoidosis. Eact patient had coagulation studies before biopsy. W excluded for outpatient investigation all patients over 70 years, patients with possible abnormal coagulatiog (abnormal prothrombin time or platelet count) or $\Phi$ known immunological defect. Premedication consi令 ted of an intramuscular injection of atropine sulphate 
$(0.5 \mathrm{mg})$ and hydroxyzine dichlorhydrate $(50 \mathrm{mg})$ unless specifically contraindicated. Patients underwent the procedure in the supine position.

Topical anaesthesia of the nose was with 5\% lignocaine solution and anaesthesia of the pharyngolaryngeal zone with $2 \%$ lignocaine. In most cases the fibreoptic bronchoscope (Olympus BF 1T10) was introduced transnasally. Continuous cardiac monitoring was not performed during the procedure but in some patients arterial oxygen saturation was measured continuously. Bronchoalveolar lavage was performed in the right middle lobe or the lingula. After the subsegmental bronchus had been selected the patient was instructed to breathe slowly and quietly. The small closed forceps were extended into the bronchus. When a resistance was met the forceps was withdrawn 1-2 cm, opened, and advanced again until resistance was felt. The forceps were then closed and the biopsy specimen was taken unless chest pain was experienced. The numbers of specimens per patient are shown in table 1.

Once the procedure was completed patients stayed under medical observation for one hour, or more if necessary (a rest room was in the bronchoscopy area). A chest radiograph was performed only if a complication was suspected-that is, if there was chest pain, haemoptysis, or breathlessness. All patients were instructed to return if unusual symptoms developed.

\section{Results}

Transbronchial biopsies were performed in 174 outpatients; most patients had three $(42 \%)$ or four $(31 \%)$ biopsy specimens taken. In 152 patients $(87 \%)$ at least one fragment consisted of alveolar tissue and in 128 patients $(74 \%)$ at least two fragments. The final diagnoses obtained by bronchoalveolar lavage and transbronchial biopsy are shown in table 2 .

The complications are summarised in table 3. No major complications were encountered. Six patients developed a pneumothorax. In four patients this was suspected within an hour of the bronchoscopy, when the patient developed chest pain or dyspnoea, and was confirmed by radiography. Three of the four patients underwent transthoracic needle aspiration and were discharged after 48 hours' observation; the fourth patient required chest tube drainage and remained in

Table 1 Number of biopsy specimens taken

\begin{tabular}{ll}
\hline No of specimens & No (\%) of patients \\
\hline 1 & $6(3.4)$ \\
2 & $20(11)$ \\
3 & $72(42)$ \\
4 & $54(31)$ \\
5 & $22(13)$ \\
\hline
\end{tabular}

Table 2 Final diagnosis in 174 patients

\begin{tabular}{lc}
\hline & No of patients \\
\hline Sarcoidosis & 74 \\
Hypersensitivity pneumonitis & 30 \\
Fibrosis & 22 \\
Pneumoconiosis & 12 \\
Lymphangitis carcinomatosis & 4 \\
Other: & 3 \\
Tuberculosis & 2 \\
Alveolar proteinosis & 2 \\
Histiocytosis X & 2 \\
Lymphangiomatosis & 1 \\
Alveolar microlithiasis & 1 \\
Amyloidosis & 1 \\
Schistosomiasis & 154 \\
& 20 \\
No diagnosis & 174 \\
\hline
\end{tabular}

hospital for six days. In two patients pneumothorax was diagnosed only after discharge from the bronchoscopy suite. They did not require admission to hospital. Haemoptysis of over $30 \mathrm{ml}$ occurred in only two patients and resolved spontaneously. Three patients developed pyrexia of over $38.5^{\circ} \mathrm{C}$. In two this settled spontaneously within 24 hours, but one patient developed a new infiltrate in the right middle lobe and received antibiotics for presumed pneumonia.

Thus six of the 174 patients undergoing fibreoptic bronchoscopy as an outpatient required hospital admission for a complication (3.4\%). Among the 188 patients undergoing fibreoptic bronchoscopy as an inpatient at the same time the complication rate was similar. Eight pneumothoraces occurred, all diagnosed within two hours of the procedure, of which three required intercostal drainage. There were five cases of haemoptysis of $30 \mathrm{ml}$ or more, all subsiding spontaneously.

\section{Discussion}

Fibreoptic bronchoscopy with transbronchial biopsy is a widely accepted technique for the diagnosis of diffuse lung disease. ${ }^{1914}$ Several complications, however, have been reported. ${ }^{51516}$ Early studies, concerned with patients with diffuse pulmonary disease undergoing transbronchial biopsy through a rigid bronchoscope and with large forceps $(2 \times 4 \mathrm{~mm})$, reported a $14 \%$ incidence of pneumothorax in 450 patients. ${ }^{2}$ A questionnaire sent to some centres in the

Table 3 Complications after transbronchial bịpsy

\begin{tabular}{ll}
\hline & No of patients \\
\hline Pneumothorax & 6 \\
Bleeding $(>30 \mathrm{ml})$ & 2 \\
Fever $\left(>38^{\circ} \mathrm{C}\right)$ & 3 \\
Death & 0 \\
\hline
\end{tabular}


United States and Canada by Herf et al in 1977 found an incidence of pneumothorax of $5.5 \%$ in 2628 procedures. ${ }^{15}$ Although fluoroscopy has been used for transbronchial biopsy for several years ${ }^{1718}$ in an attempt to prevent rupture of the pleura, recent studies suggest that the procedure is safe without fluoroscopy ${ }^{7-9} 14$ When Anders compared 112 transbronchial biopsies performed with and 135 performed without fluoroscopy ${ }^{8}$ the complication rates for pneumothorax, fever, and haemoptysis were similar. ${ }^{8}$ The incidence of pneumothorax when transbronchial biopsy is performed without fluoroscopy is around $2-3 \%$ in the published series (table 4). Scheinhorn suggested that the probable reason for the different incidences of pneumothorax is related to the size of forceps used. ${ }^{19}$ In the first studies reported the forceps cups were $2 \times 4 \mathrm{~mm}$ whereas the usual size now is $1.5 \times 2 \mathrm{~mm}^{19}$

The second problem under discussion is whether patients need to be admitted to hospital before transbronchial biopsy. Since its introduction 20 years ago, fibreoptic bronchoscopy has been shown to be very safe. ${ }^{5-20}$ This has been shown in patients admitted to hospital ${ }^{10}$ and in patients undergoing transbronchial biopsy as an outpatient procedure but with fluoroscopy. ${ }^{20}$ In the latter study of 148 patients the pneumothorax rate was very low (0.68\%). After the procedure the patients underwent fluoroscopic screening for pneumothorax and were discharged after observation for one hour. ${ }^{12}$ In our study no fluoroscopy was used during or after biopsy, because fluoroscopy was not easily available in our institution and because of our previous experience of radiography performed six and 24 hours after the procedure. ${ }^{21}$ In the previous study we found four cases of pneumothorax among 69 consecutive patients (6\%) and in each case this had been suspected clinically. In the present study of 174 outpatients four pneumothoraces were diagnosed within one hour and only two diagnoses were delayed (these two patients were symptomless and the pneumothorax was small). Herf et al reported one death due to tension pneumothorax six to eight hours after a transbronchial biopsy. ${ }^{15}$ To our knowledge this is the only case of a fatal pneumo- thorax. In other reports death has occurred during the procedure or immediately after it was completed and $\frac{}{6}$ has been due to bleeding, cerebral air embolism, or myocardial infarction. ${ }^{4516}$

The pneumothorax rates were similar in those $\stackrel{\mathbb{Q}}{\Omega}$ undergoing fibreoptic bronchoscopy as an outpatient and as an inpatient $(6 / 174 v 8 / 188)$. Among the $\vec{\circ}$

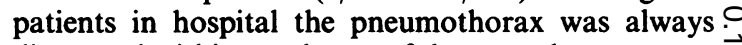
diagnosed within two hours of the procedure.

In our experience no major complications have $\stackrel{\omega}{\sigma}$ occurred after one hour. Bleeding has always occurred $\vec{x}$ at the time of transbronchial biopsy, ${ }^{7811}$ and fever, though relatively common (10 patients out of 68 in one

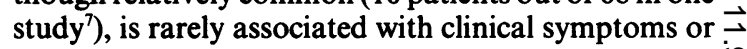
radiological signs.

In conclusion, fibreoptic bronchoscopy with trans-

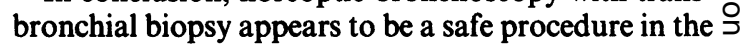
hands of an experienced physician. Fluoroscopy is not $\vec{z}$ essential and using the sensation of resistance to 2 determine the site of biopsy allows transbronchial biopsy to be carried out with a low complication rate. No major problems occur beyond the first hour except $\stackrel{\Phi}{-}$ for pyrexia. Thus patients need not be admitted to $\overrightarrow{0}$ hospital solely for transbronchial biopsy in the absence of other risk factors, such as severe cardiopulmonary disease or abnormal coagulation.

\section{References}

1 Fulkerson WJ. Current concepts in fiberoptic bronchoscopy. N Engl J Med 1984;311:511-5.

2 Andersen HA, Fontana RS. Transbronchoscopic lungō biopsy for diffuse pulmonary diseases: technique and results in 450 cases. Chest 1972;62:125-6.

3 Credle WF, Smiddy JF, Elliot RC. Complications of fiberoptic bronchoscopy. Am Rev Respir Dis 1974;109:67-72.

4 Suratt PM, Smiddy JF, Gruber B. Deaths and complica- ्ָ tions associated with fiberoptic bronchoscopy. Chest $\bar{\sigma}$ 1976;69:747-51.

5 Pereira W, Kovnat DM, Snider GL. A prospective cooperative study of complications following flexible 3 fiberoptic bronchoscopy. Chest 1978;73:813-6.

6 Sokolonski HW, Burgher LW, Jones FL, Patterson JR, 을 Selecky PA. ATS Official Position Paper: guidelines for fiberoptic bronchoscopy in adults. Am Rev Respir Dis

Table 4 Complications after transbronchial biopsy in published series

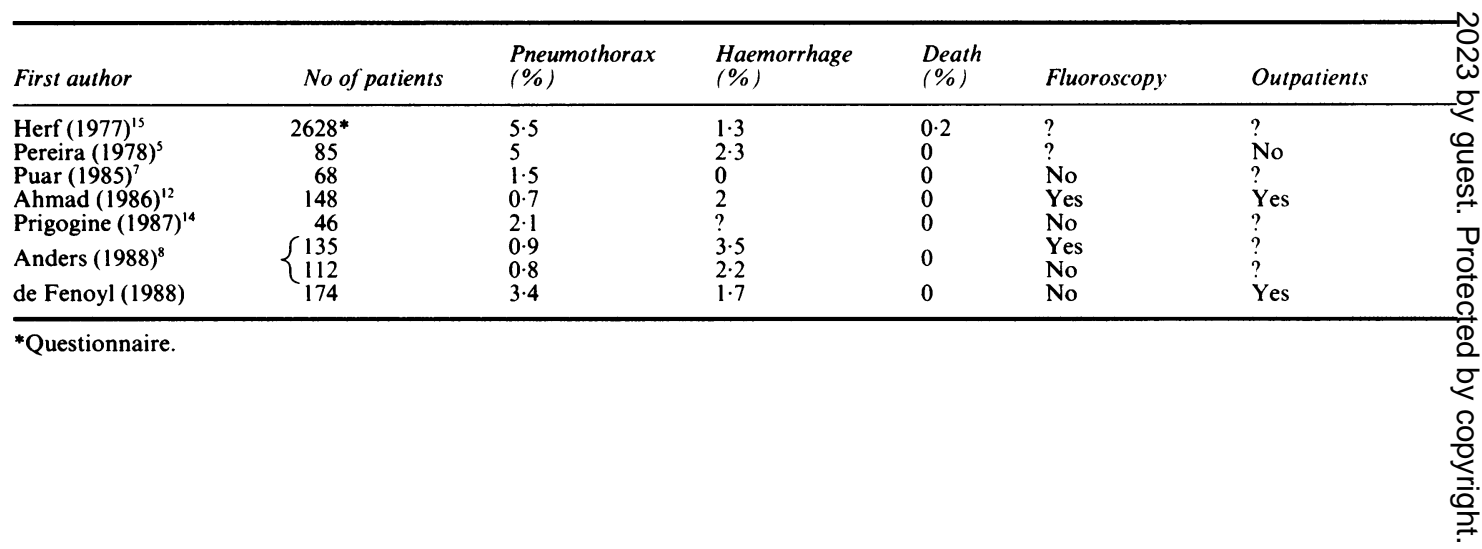


Transbronchial biopsy without fluoroscopy 1987;136:1066.

7 Puar HS, Young RC, Armstrong EM. Bronchial and transbronchial lung biopsy without fluoroscopy in sarcoidosis. Chest 1985;87:303-6.

8 Anders GT, Johnson JE, Bush BA, Matthews JI. Transbronchial biopsy without fluoroscopy. A seven year perspective. Chest 1988;94:557-60.

9 Armstrong EM. Transbronchial lung biopsy without fluoroscopy (letter). Chest 1987;92:187-8.

10 Ackart RS, Foreman DR, Klayton RJ, Donlan CJ, Munzel TL, Schuler MA. Fiberoptic bronchoscopy in outpatient facilities, 1982. Arch Intern Med 1983;143:30-1.

11 Khan MA. Fiberoptic bronchoscopy revisited. Chest 1978;74:119-20.

12 Ahmad M, Livingston DR, Golish JA, Mehta AC, Wiedemann HP. The safety of outpatient transbronchial biopsy. Chest 1986;90:403-5.

13 Aelony Y. Outpatient fiberoptic bronchoscopies (letter). Arch Intern Med 1983;143:1837.

14 Prigogine T, Schmerber J. Transbronchial lung biopsy without fluoroscopy [letter]. Chest 1987;92:187-8.
15 Herf SM, Suratt PM, Arora NS. Deaths and complications associated with transbronchial lung biopsy. Am Rev Respir Dis 1977;115:708-11.

16 Strange C, Heffner JE, Collins BS, Brown FM, Sahn SA. Pulmonary hemorrhage and air embolism complicating transbronchial biopsy in pulmonary amyloidosis. Chest 1987;93:367-8.

17 Hooper RG, Tellis CJ, Hunt KK. Methodology in transbronchial lung biopsy [letter]. Chest 1972;72:130.

18 Zavala DC. Methodology in transbronchial lung biopsy [letter]. Chest 1972;72:130-1.

19 Scheinhorn DJ, Joyner LR, Whitcomb ME. Transbronchial forceps lung biopsy through fiberoptic bronchoscope in Pneumocystis carinii pneumonia. Chest 1974;66:294-5.

20 Donlan CJ, Foreman DR, Klayton RJ. Fiberoptic bronchoscopy in nonhospitalized patients. Arch Intern Med 1978;138:698-9.

21 de Fenoyl O, Capron F, Leclerc P, Rochemaure J. Transbronchial biopsy without fluoroscopy in diffuse lung disease: a safe technique? [abstract]. Bull Eur. Physiopathol Respir 1986;22(suppl 8):67S. 